\title{
Width of Nucleation Region of Si Nanocrystal Grains Prepared by Pulsed Laser Ablation with Different Laser Fluence
}

\author{
Zechao Deng, ${ }^{1,2}$ Xuexia Pang, ${ }^{1,2}$ Xuecheng Ding, ${ }^{1,2}$ Lizhi Chu, ${ }^{1,2}$ and Yinglong Wang \\ ${ }^{1}$ College of Physics Science and Technology, Hebei University, Baoding 071002, China \\ ${ }^{2}$ Key Laboratory of Photo-Electricity Information Materials of Hebei Province, Baoding 071002, China \\ Correspondence should be addressed to Yinglong Wang; hdwangyl@hbu.cn
}

Received 28 November 2014; Accepted 13 March 2015

Academic Editor: Vincent Gomes

Copyright (c) 2015 Zechao Deng et al. This is an open access article distributed under the Creative Commons Attribution License, which permits unrestricted use, distribution, and reproduction in any medium, provided the original work is properly cited.

\begin{abstract}
Si nanocrystal grains were prepared by pulsed laser ablation with different laser fluence in Ar gas of $10 \mathrm{~Pa}$ at room temperature. The as-formed grains in the space deposited on the substrates and distributed in a certain range apart from target. According to the depositing position and radius of grains, the nucleation locations of grains in the space were roughly calculated. The results indicated that the width of nucleation region broadened with increasing of ion densities diagnosed by Langmuir probe, which increased with laser fluence from $2 \mathrm{~J} / \mathrm{cm}^{2}$ to $6 \mathrm{~J} / \mathrm{cm}^{2}$; that is, width of nucleation region broadened with addition of laser fluence. At the same time, the width broadened with the terminal formation position moving backward and the initial formation position of grains moving toward ablated spot. The experimental results were explained reasonably by nucleation thermokinetic theory.
\end{abstract}

\section{Introduction}

Recently, in order to prepare ideal size of Si nanocrystal grains and uniform film for better applications, the works about nucleation and growth dynamics of grains gradually become hot topics. It is important to fully understand and exploit the dynamics mechanism for both practical application [1, 2] and fundamental research [3]. Among the methods of experimental and theoretical studies about Si grains, pulsed laser ablation (PLA) is one of the most common methods due to its unique advantages such as rapid thermogenic speed, high atoms concentration, and small surface contamination. As it is known, Si nanocrystal grains will come into being through collision between background gas and ablated particles, which generated by nanosecond (ns) laser ablates single crystal $\mathrm{Si}$ in inert gas environment. The nslaser ablation remarkably differs from femtosecond (fs) laser; the latter can produce grains directly in vacuum during ablation, but it is not conducive to observe the nucleation and growth process of grains $[4,5]$. Thus many techniques have been focused on ns-PLA for possessing both processes of nucleation and growth during ablated particles transmitting in background gas. In order to obtain uniform and ideal size grains by PLA, many means have been introduced, such as imposed outside force [6], changed laser wavelength [7], altered distance between target and substrate [8], elevated substrate temperature [9], and transformed background gas kind [10]. At the same time, many theoretical models have been established to understand the nucleation mechanism during laser ablation process, such as hydrodynamics model [11], nucleation division model [12], and nucleation potential of one certain size grain [13]. According to the nucleation division model, nucleation and growth of grains occur in the area of nucleation region (NR) [12]; furthermore, the mean size and size-consistency of grains directly depend on the width, so determining width of NR is an important topic. To better understand the influence of NR width on the mean size and size-consistency of grains will be helpful for more practical applications in future. The relationship of different experimental parameters with width of NR is another key point.

\section{Experimental Installation}

The single crystal Si target was ablated by a focused laser beam of $\mathrm{XeCl}(308 \mathrm{~nm}, 15 \mathrm{~ns})$. Chamber was filled with pure $\mathrm{Ar}$ 


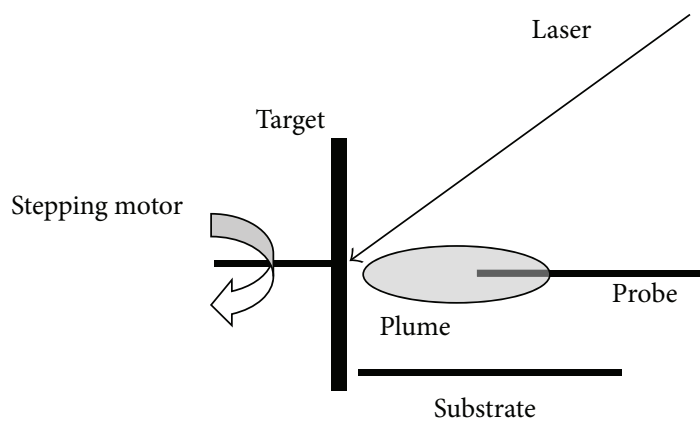

FIgURE 1: Schematic sketch of PLA apparatus.

gas of $10 \mathrm{~Pa}$ after base pressure was evacuated less than $2 \times$ $10^{-4} \mathrm{~Pa}$. Samples were deposited on two different substrates, namely, glass plates and Si (111) plates; both were parallel to plume axes and the vertical distance was $2 \mathrm{~cm}$ to ablated spot; the schematic sketch is shown as Figure 1. Laser fluence varied from $2 \mathrm{~J} / \mathrm{cm}^{2}$ to $6 \mathrm{~J} / \mathrm{cm}^{2}$ and pulse frequency was $1 \mathrm{~Hz}$. The thickness of deposited films was $200 \mathrm{~nm}$ or so, and films deposited on glass plates were analyzed by Raman scattering, while films deposited on Si (111) plates were characterized by scanning electron microscopy (SEM). Langmuir probe made of tungsten material was located along plume axes and vertical to the target surface. Probe tip was penetrated into the center of the plume and the distance to target surface was $2 \mathrm{~cm}$.

\section{Experimental Results}

All results of experiments showed definitely that the deposited grains distributed in an area on substrates. Mean size of grains first increased and then decreased with addition of lateral distance to target with different laser fluence. Furthermore, width of the area broadened bidirectionally with increasing laser fluence; that is to say, when terminal position (away from ablated spot) of detected grains shifted backward, the initial position (close to ablated spot) of detected grains moved toward target at the same time. The measured deposition location of grains on substrates $(x)$ corresponding to different laser fluence is listed in Table 1; $x_{0}$ is nucleation location of calculation in the space (the calculation details are shown in following section).

According to the similar distribution rule of grains on substrates, SEM graphs of deposited samples with laser fluence of $3 \mathrm{~J} / \mathrm{cm}^{2}$ are selected out to be representative, which are shown as Figure 2.

Figures $2(\mathrm{a})-2(\mathrm{~h})$ corresponding to the various lateral distance to target surface are $6.3 \mathrm{~mm}, 6.4 \mathrm{~mm}, 10 \mathrm{~mm}, 15 \mathrm{~mm}$, $20 \mathrm{~mm}, 30 \mathrm{~mm}, 37.4 \mathrm{~mm}$, and $37.5 \mathrm{~mm}$, respectively. It is obviously that no grains can be found in Figures 2(a) and 2(h); furthermore, at the same position of glass plates, Raman spectra of samples indicate that the deposited films are also amorphous. Figures 2(b) 2(g) show the films contain grains, $6.4 \mathrm{~mm}$ and $37.4 \mathrm{~mm}$ are initial and terminal positions where detect grains on substrates, and the mean size on the substrates located at $15 \mathrm{~mm}$ from target is biggest.
Raman spectra of samples with laser fluence of $3 \mathrm{~J} / \mathrm{cm}^{2}$, corresponding to the location from $6.4 \mathrm{~mm}$ to $37.4 \mathrm{~mm}$, are shown as in Figure 3.

In Figure 3, the main peaks of spectra corresponding to the location from $6.4 \sim 37.4 \mathrm{~mm}$ are $515.995 \mathrm{~cm}^{-1}$, $518.981 \mathrm{~cm}^{-1}, 519.474 \mathrm{~cm}^{-1}, 518.488 \mathrm{~cm}^{-1}, 515.995 \mathrm{~cm}^{-1}$, and $514.502 \mathrm{~cm}^{-1}$, respectively. All values of the peaks are close to the characteristic peak value of single crystal $\mathrm{Si}$, which is $520 \mathrm{~cm}^{-1}$; calculation results of $X_{c}$ indicate that the crystalline grains formed on the base of formula

$$
X_{c}=\frac{\left(I_{c}+I_{m}\right)}{\left(I_{c}+I_{m}+I_{a}\right)},
$$

where $X_{c}$ is crystalline volume fraction of samples and $I_{c}$, $I_{m}$, and $I_{a}$ are Raman spectra intensity corresponding to $520 \mathrm{~cm}^{-1}, 510 \mathrm{~cm}^{-1}$, and $480 \mathrm{~cm}^{-1}$, respectively. Figure 3 also shows that the main spectra peaks first shift right and then left, which indicates that the mean size of grains first increases and then decreases by the formula [14] of

$$
d=2 \pi\left(\frac{B}{w}\right)^{1 / 2}
$$

where $d$ represents diameter of grain, $\omega$ is peak shift of Raman for the grain as compared to single crystal Si; $B=$ $2.0 \mathrm{~cm}^{-1} \cdot \mathrm{nm}^{2}$. The measure results changing rule agrees with statistic data by SEM.

\section{Calculation of Nucleation Region Location}

Ablated Si particles (which contain $\mathrm{Si}$ atoms and ions; electrons are neglected here) spray from target after laser ablation; their kinetic energy wears down through collisions with background gas during transportation. According to the hydrodynamics model [11], slowing coefficient of ablated $\mathrm{Si}$ atom (atom is equated to ion) is $a_{\mathrm{Si}}=C S_{\mathrm{Si}} \rho / 2$, where $C$ is proportional constant, $S_{\mathrm{Si}}$ is cross section of $\mathrm{Si}$ atom, and $\rho$ is density of ambient gas. The mean size of nucleated grains and structure of samples will change for different gas sort and gas pressure (or $\rho$ ), which have been confirmed by several experiments [11-13]. Fu et al. [12] proposed that the nucleation division model shows that nucleation will happen when ablated $\mathrm{Si}$ atoms' thermal motion temperature $\left(T^{\prime}\right)$ is lower than the melting point of single crystal Si. According to thermodynamic equation, when ablated atoms nucleate, they obey the formula

$$
k_{B} T=\frac{m_{\mathrm{Si}} v_{\mathrm{Si}}^{2}}{2}=\frac{m_{\Delta} v_{\Delta}^{2}}{2 A^{2}}
$$

and $m_{\mathrm{Si}} / m_{\Delta}=\left(r_{\mathrm{Si}} / r_{\Delta}\right)^{3}$, where $k_{B}$ is Boltzmann constant, $T$ is temperature of melting point for atoms nucleation, $m_{\mathrm{Si}}$ and $r_{\mathrm{Si}}, m_{\Delta}$, and $r_{\Delta}$ are the mass and radius of $\mathrm{Si}$ atom and grain, respectively, and $A$ is energy conversion coefficient between ablated atom and grain. $v_{\mathrm{Si}}$ and $v_{\Delta}$ are velocity of ablated $\mathrm{Si}$ atom and grain; the direction of them is parallel to plume axes too. The schematic diagram of nucleation and motion for one grain is shown in Figure 4. 
TABLE 1: Deposition location of grains on substrates and nucleation location in the space with different laser fluence.

\begin{tabular}{lcccccc}
\hline Sample & A & B & C & D & E & F \\
\hline Laser fluence $\left[\mathrm{J} / \mathrm{cm}^{2}\right]$ & 2 & 2.5 & 3 & 3.5 & 4.5 & 6 \\
$x[\mathrm{~mm}]$ & $7.7-31.4$ & $7.2-34.8$ & $6.4-37.4$ & $5.3-42.8$ & $4.3-45.0$ & $3.9-58.4$ \\
$x_{0}[\mathrm{~mm}]$ & $3.5-28.9$ & $3.3-32.7$ & $3.0-34.5$ & $2.5-41.6$ & $2.2-43.8$ & $1.8-56.7$ \\
NR width & 25.4 & 29.4 & 31.5 & 39.1 & 41.6 & 54.9 \\
\hline
\end{tabular}

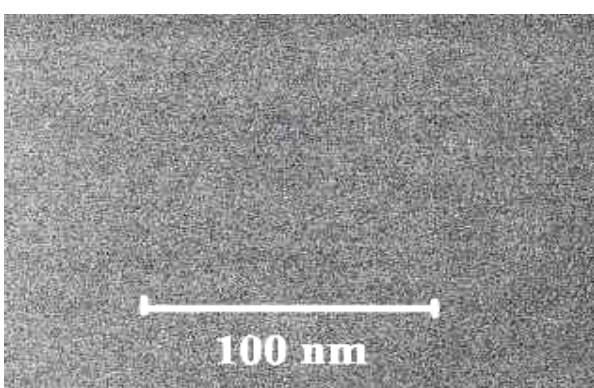

(a)

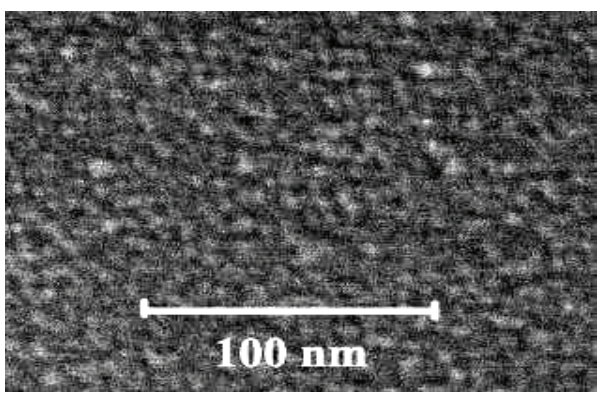

(c)

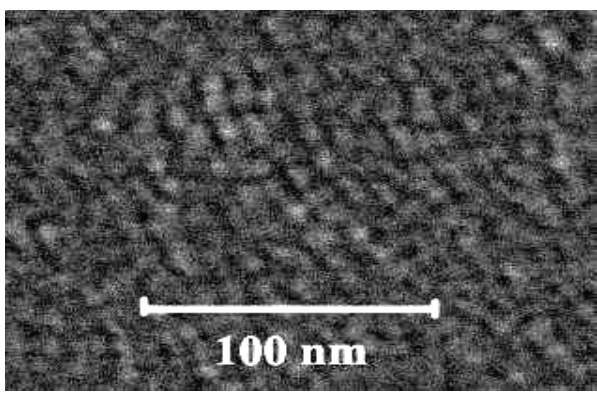

(e)

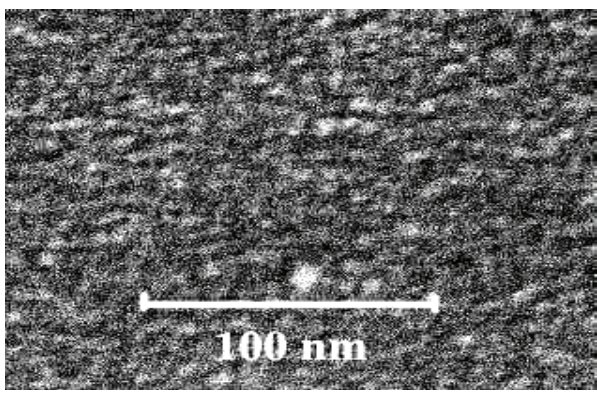

(g)

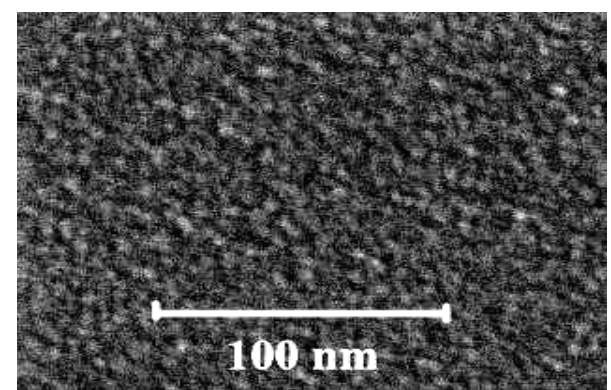

(b)

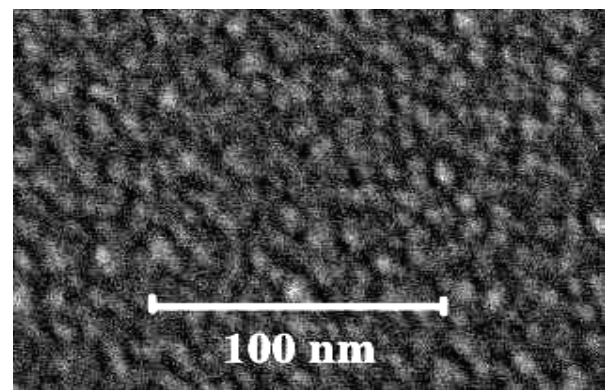

(d)

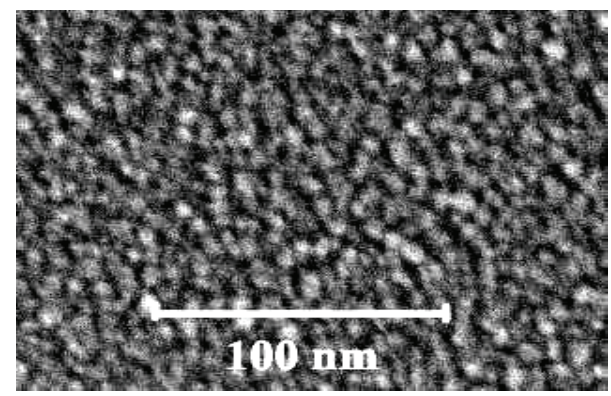

(f)

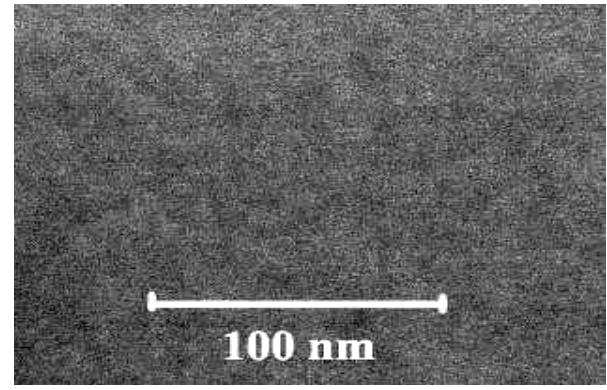

(h)

FIGURE 2: SEM photographs of samples with laser fluence of $3 \mathrm{~J} / \mathrm{cm}^{2}$. (a)-(h) Corresponding to the various lateral distance to target surface are $6.3 \mathrm{~mm}, 6.4 \mathrm{~mm}, 10 \mathrm{~mm}, 15 \mathrm{~mm}, 20 \mathrm{~mm}, 30 \mathrm{~mm}, 37.4 \mathrm{~mm}$, and $37.5 \mathrm{~mm}$. 


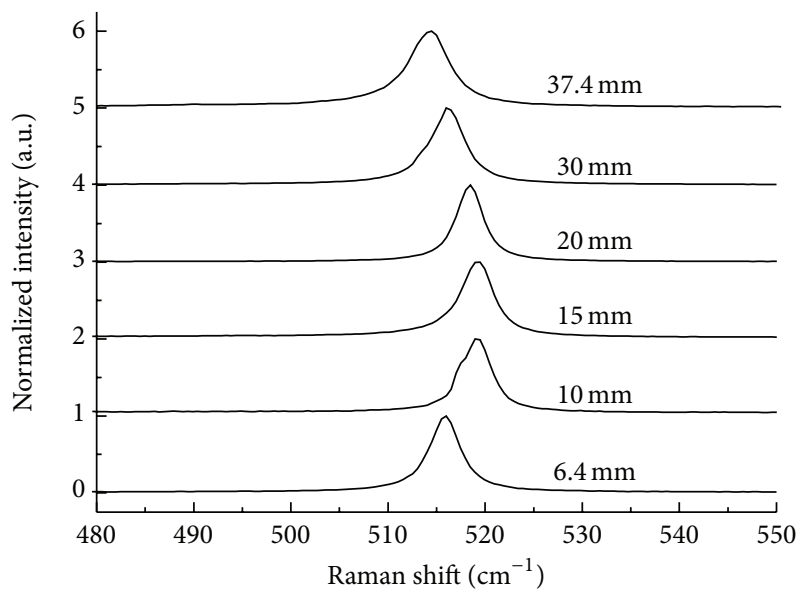

FIGURE 3: Raman spectra of samples with laser fluence of $3 \mathrm{~J} / \mathrm{cm}^{2}$, and the sample positions relative to the target are $6.4 \mathrm{~mm}, 10 \mathrm{~mm}$, $15 \mathrm{~mm}, 20 \mathrm{~mm}, 30 \mathrm{~mm}$, and $37.4 \mathrm{~mm}$.

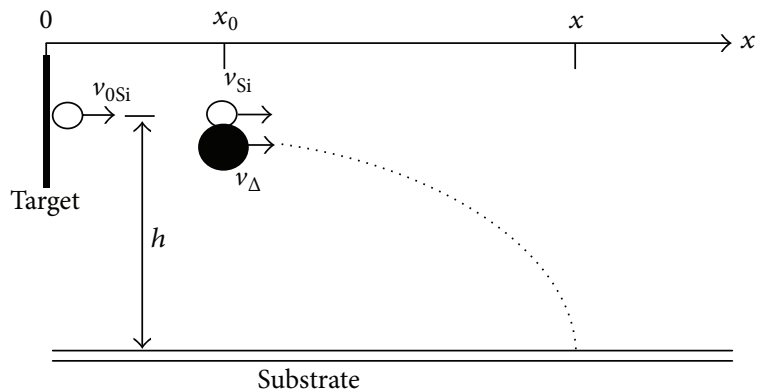

FIGURE 4: Schematic diagram of nucleation and motion of grain.

During transportation process, collision cross section between ablated $\mathrm{Si}$ atom and gas atom is

$$
S_{\mathrm{Si}-\mathrm{Ar}}=\pi\left(r_{\mathrm{Ar}}+r_{\mathrm{Si}}\right)^{2} .
$$

The collision cross section between formed grain and gas atom is

$$
S_{\Delta-\mathrm{Ar}}=\pi\left(r_{\mathrm{Ar}}+r_{\Delta}\right)^{2}
$$

$r_{\mathrm{Ar}}$ is radius of Ar atom.

Formed grains will fall onto substrates through flat parabolic motion. Formula for spatial position of grain formation based on the hydrodynamics model [11] is

$$
\begin{aligned}
& x_{0}= x-A v_{0 \mathrm{Si}} e^{-\left[1-\left(r_{\mathrm{Ar}}+r_{\Delta}\right)^{2} r_{\mathrm{Si}}{ }^{3} /\left(r_{\mathrm{Ar}}+r_{\mathrm{Si}}\right)^{2} r_{\Delta}{ }^{3}\right] \alpha_{\mathrm{Si}} x_{0} / m_{\mathrm{si}}} \\
& \cdot \sqrt{\frac{2 h}{g}}{\sqrt{\left(\frac{r_{\mathrm{Si}}}{r_{\Delta}}\right)^{3}}}^{3}
\end{aligned}
$$

where $v_{0 \mathrm{Si}}$ is initial velocity of ablated $\mathrm{Si}$ atoms [15] and its direction is parallel to plume axes too, $x$ is position of deposited grains on substrate, $h$ represents vertical distance from ablated spot to substrates, which is equal to $2 \mathrm{~cm}$ in this work, and $g$ is acceleration of gravity.
In order to calculate conveniently, it is assumed that the plume is limited in the cylinder with ablation spot as area of base in this work, and the size of deposited grains on substrates is the value of initial nucleation; that is to say, the growth process in the space is not considered here. On the base formula (6), the position of grains formation and width of NR in the space are calculated, which are listed in Table 1. Obviously, there is a shift toward target for nucleation position contrasting to the detection value on substrates. Furthermore, with laser fluence increasing, the tendency of width of NR broadening is bidirectional.

\section{Theoretical Analysis}

On the base of the process of ablation, results of numerical simulation show that velocities of ablated particles present the Maxwell distribution, which are maximum at front of plume and minimum near target (plume tail); the number of particles corresponding to two parts (maximum and minimum velocities) is also fewer than those with the most probable velocity. According to formula (3), $T^{\prime}$ of particles is lower for smaller velocity, so it will easily reach the nucleation condition first through collision in constant pressure gas. It implies that once supersaturation $\left(\rho^{\prime}\right)$ satisfies condition, nucleation will happen first near target, which is also proved by Makimura et al. [16, 17]. Obviously, $T^{\prime}$ is higher for greater velocity of ablated particles; then they need to experience much more collisions before nucleation; therefore, the nucleation position should be comparatively farther from target. For the number of particles with the most probable velocity being the greatest, the growth probability of nucleated grains by these particles is relatively large, which causes the final size of these grains to be larger, so the grains' size on substrates first increases, after reaching the maximum value, and then decreases. When the ablated particles spray from target just after pulsed laser off, although $\rho^{\prime}$ is very big, but $T^{\prime}$ is much higher than melting point, so they cannot nucleate [12]. After long distance transportation in gas (out of NR width), $T^{\prime}$ is lower than melting point, while $\rho^{\prime}$ is too low to nucleate, so the width of NR distributes in a certain area apart from target. In other words, as long as any one of $T^{\prime}$ and $\rho^{\prime}$ does not comply with the condition, nucleation will not happen.

The processes of ablation with different laser fluence are also simulated through Monte Carlo method in this work. The results show that initial velocity and sum numbers of ablated particles elevate directly proportional to laser fluence increasing; at the same time, the plume volume $(V)$ becomes bigger too. Then a new problem emerges, which is how does ablated particles density change? We cannot directly get an answer through the formula of $\rho^{\prime}=M / V$, because both $M$ and $V$ are variable. $M$ is total mass of abated particles.

In order to resolve the problem, Langmuir probe was applied to measure the densities of ablated ions in order to understand the change rule of ablated particles. The probe was vertical to the target surface along the plume axes, and the probe tip was located within the center of plume. The delay time for collecting signal was $15 \mu \mathrm{s}$; voltage of probe changed from $-30 \mathrm{~V}$ to $50 \mathrm{~V}$. By fitting and analyzing the 


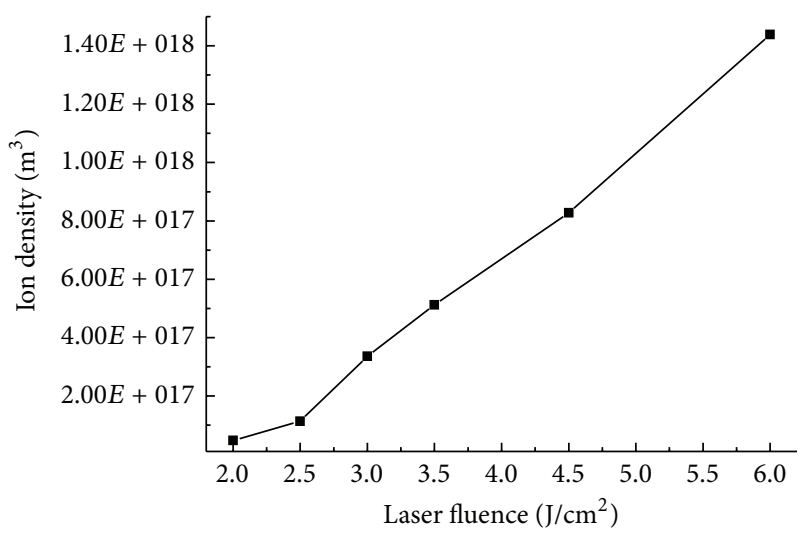

FIGURE 5: Si ion densities versus different laser fluence. Laser fluence is $2 \mathrm{~J} / \mathrm{cm}^{2}, 2.5 \mathrm{~J} / \mathrm{cm}^{2}, 3.0 \mathrm{~J} / \mathrm{cm}^{2}, 3.5 \mathrm{~J} / \mathrm{cm}^{2}, 4.5$, and $6.0 \mathrm{~J} / \mathrm{cm}^{2}$.

$I-V$ curves obtained from probe, the change rule of Si ion densities is shown as in Figure 5. Obviously, ion densities rise with addition of laser fluence linearly, which are suitable for Si atoms too.

When laser fluence rises, the initial velocity and density of ablated particles increase simultaneously, which lead to intensive collision with gas atoms. Therefore, the kinetic energy of some ablated particles near target decreases rapidly and thermal motion temperature gets down to T; thus nucleation appears and grains form. With laser fluence increasing continually, the collision will become much more intensive, grains would form at position more close to target surface naturally, and then the initial formation position of grains moves toward ablated spot. At the same time, the most unnucleated particles with higher thermal motion temperature have to experience much more necessary collisions; then the temperature could decrease to $T$, which causes them to translate farther path. So the terminal nucleation position shifts backward with laser fluence increasing, which results in the fact that width of NR of grains in the space broadens bidirectionally.

\section{Conclusion}

In summary, we have prepared Si nanocrystal grains by pulsed laser ablation through changing laser fluence; the width of NR is calculated on the basis of experimental results, which broaden from $25.4 \mathrm{~mm}$ to $54.9 \mathrm{~mm}$ with addition of laser fluence from $2 \mathrm{~J} / \mathrm{cm}^{2}$ to $6 \mathrm{~J} / \mathrm{cm}^{2}$. The change rule of ion densities is studied by Langmuir probe; results indicate that the ion densities increase with laser fluence raising, which results in the more intensive collisions between ablated particles and background gas. From the analysis of the thermokinetic process and calculated results, a good explanation for the phenomenon of broadened width of NR can be given. The results indicate that the nucleation and growth of grains are decided by both the supersaturation and thermal motion temperature of ablated particles. It may support theoretical foundation for further studying the nucleation and growth process for nanocrystal grains of $\mathrm{Si}$ as well as other materials in gas phase.

\section{Conflict of Interests}

The authors declare that there is no conflict of interests regarding the publication of this paper.

\section{Acknowledgments}

This project is supported by the NSF of Hebei Province (E2012201035, A2015201166) and the Research Project of Colleges and University of Hebei Province (Q2012084, 2013252), China.

\section{References}

[1] G. Masini, L. Colace, and G. Assanto, "Si based optoelectronics for communications," Materials Science and Engineering B: Solid-State Materials for Advanced Technology, vol. 89, no. 1-3, pp. 2-9, 2002.

[2] A. la Magna, P. Alippi, V. Privitera, and G. Fortunato, "Role of light scattering in excimer laser annealing of Si," Applied Physics Letters, vol. 86, no. 16, Article ID 161905, 3 pages, 2005.

[3] S. Lugomer, A. Maksimović, A. Karacs, and A. L. Toth, "Nanostructuring of a silicon surface by laser redeposition of Si vapor," Journal of Applied Physics, vol. 106, no. 11, pp. 114308-114321, 2009.

[4] S. Amoruso, R. Bruzzese, X. Wang, and J. Xia, "Propagation of a femtosecond pulsed laser ablation plume into a background atmosphere," Applied Physics Letters, vol. 92, no. 4, Article ID 041503, 2008.

[5] T. Donnelly, J. G. Lunney, S. Amoruso, R. Bruzzese, X. Wang, and X. Ni, "Dynamics of the plumes produced by ultrafast laser ablation of metals," Journal of Applied Physics, vol. 108, no. 4, Article ID 043309, 2010.

[6] A. Lorusso, V. Nassisi, G. Congedo, N. Lovergine, L. Velardi, and P. Prete, "Pulsed plasma ion source to create Si nanocrystals in $\mathrm{SiO}_{2}$ substrates," Applied Surface Science, vol. 255, no. 10, pp. 5401-5404, 2009.

[7] Y. Zhou, B. X. Wu, S. Tao, A. Forsman, and Y. B. Gao, "Physical mechanism of silicon ablation with long nanosecond laser pulses at $1064 \mathrm{~nm}$ through time-resolved observation," Applied Surface Science, vol. 257, no. 7, pp. 2886-2890, 2011.

[8] D. H. Lowndes, C. M. Rouleau, T. Thundat, G. Duscher, E. A. Kenik, and S. J. Pennycook, "Silicon and zinc telluride nanoparticles synthesized by pulsed laser ablation: size distributions and nanoscale structure," Applied Surface Science, vol. 127-129, pp. 355-361, 1998.

[9] R. Heimburger, N. Deßmann, T. Teubner, H.-P. Schramm, T. Boeck, and R. Fornari, "Polycrystalline silicon films on glass grown by amorphous-liquid-crystalline transition at temperatures below $330^{\circ}$ C," Thin Solid Films, vol. 520, no. 6, pp. 1784-1788, 2012.

[10] Y. L. Wang, Z. C. Deng, G. S. Fu, Y. Zhou, L. Z. Chu, and Y. C. Peng, "The average size of Si nanoparticles prepared by pulsed laser ablation in the gas mixture of $\mathrm{He} / \mathrm{Ar}, \mathrm{Ne} / \mathrm{Ar}$ or $\mathrm{He} / \mathrm{Ne}$," Thin Solid Films, vol. 515, no. 4, pp. 1897-1900, 2006.

[11] T. Yoshida, S. Takeyama, Y. Yamada, and K. Mutoh, "Nanometer-sized silicon crystallites prepared by excimer 
laser ablation in constant pressure inert gas," Applied Physics Letters, vol. 68, no. 13, pp. 1772-1774, 1996.

[12] G. S. Fu, Y. L. Wang, L. Z. Chu et al., "The size distribution of Si nanoparticles prepared by pulsed-laser ablation in pure $\mathrm{He}, \mathrm{Ar}$ or Ne gas," Europhysics Letters, vol. 69, no. 5, pp. 758-762, 2005.

[13] Y. L. Wang, Z. C. Deng, L. Z. Chu, G. S. Fu, and Y. C. Peng, "The difference of energies of $\mathrm{Si}$ atoms with single-crystalline, amorphous, free and nanoparticle configurations," Europhysics Letters, vol. 86, no. 1, Article ID 15001, 2009.

[14] J. Zi, H. Büscher, C. Falter, W. Ludwig, K. Zhang, and X. Xie, "Raman shifts in Si nanocrystals," Applied Physics Letters, vol. 69, no. 2, pp. 200-202, 1996.

[15] Y. L. Wang, Y. L. Li, and G. S. Fu, "Relation between sizedistribution of Si nanoparticles and oscillation-stabilization time of the mixed region produced during laser ablation," Nuclear Instruments and Methods in Physics Research Section B: Beam Interactions with Materials and Atoms, vol. 252, no. 2, pp. 245-248, 2006.

[16] T. Makimura, T. Mizuta, and K. Murakami, "Formation dynamics of silicon nanoparticles after laser ablation studied using plasma emission caused by second-laser decomposition," Applied Physics Letters, vol. 76, no. 11, pp. 1401-1403, 2000.

[17] T. Makimura, T. Mizuta, T. Takahashi, and K. Murakami, "In situ size measurement of Si nanoparticles and formation dynamics after laser ablation," Applied Physics A, vol. 79, no. 46, pp. 819-821, 2004. 

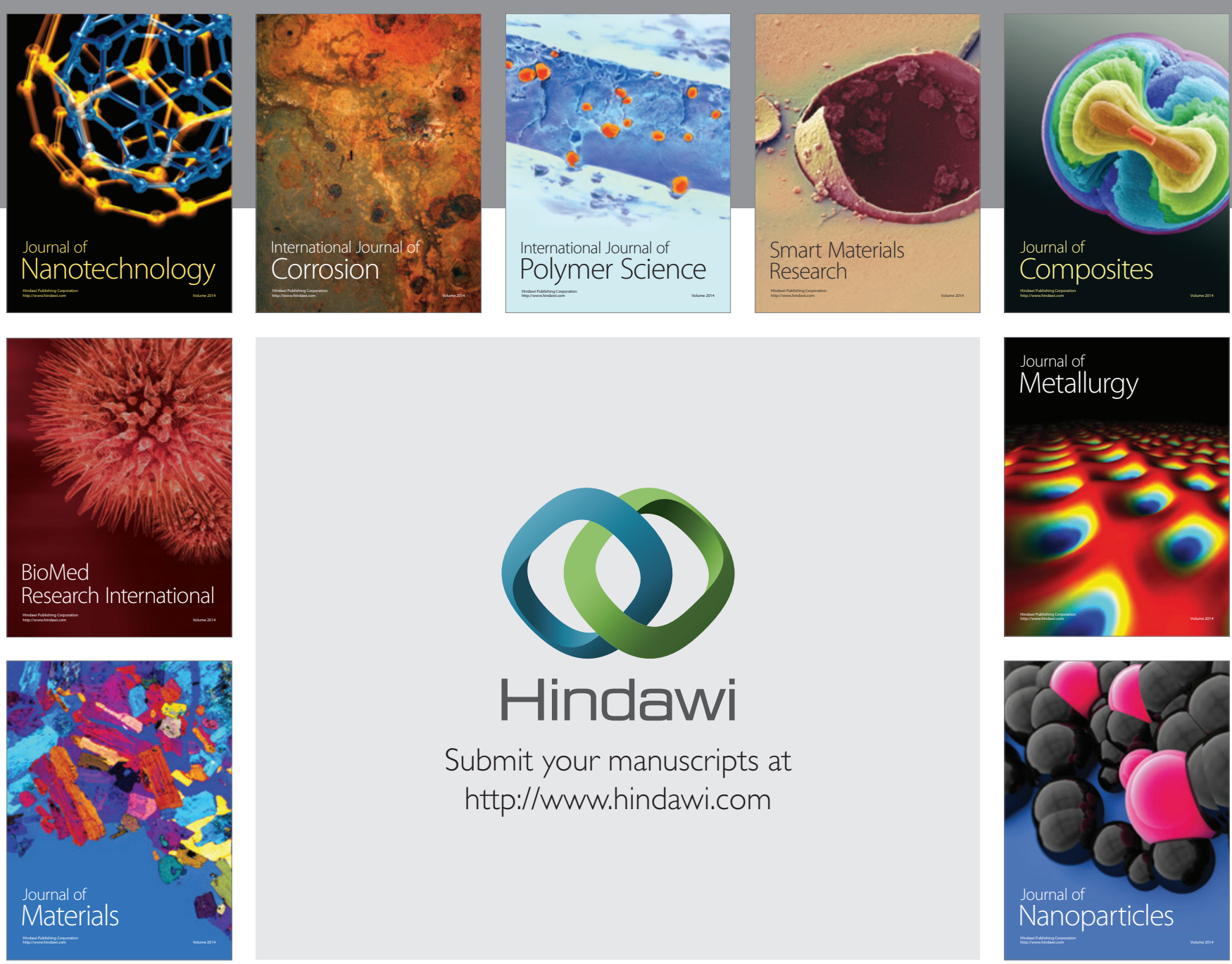

Submit your manuscripts at http://www.hindawi.com
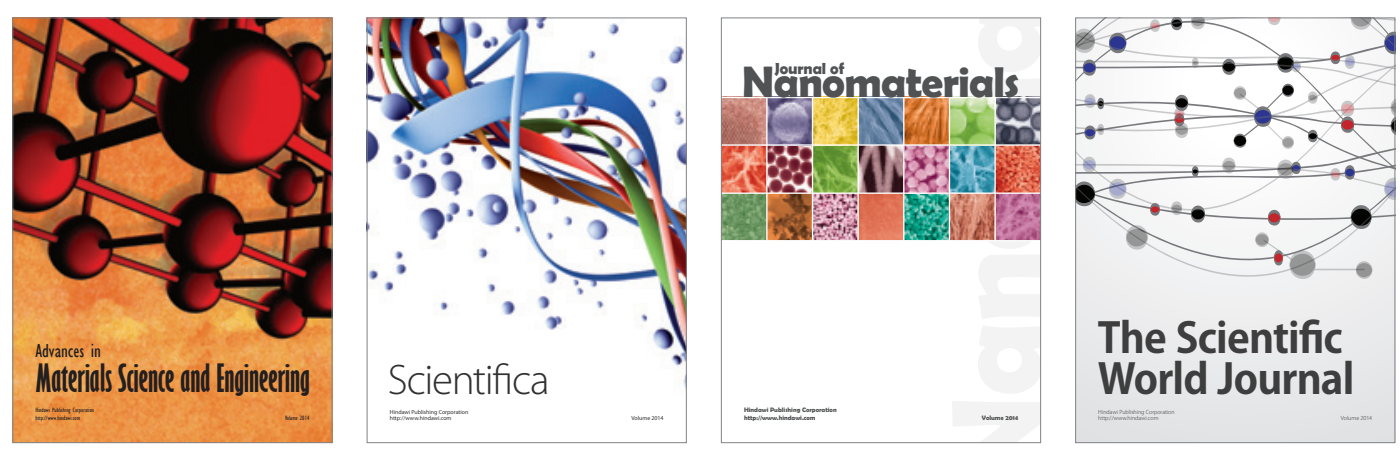

\section{The Scientific World Journal}
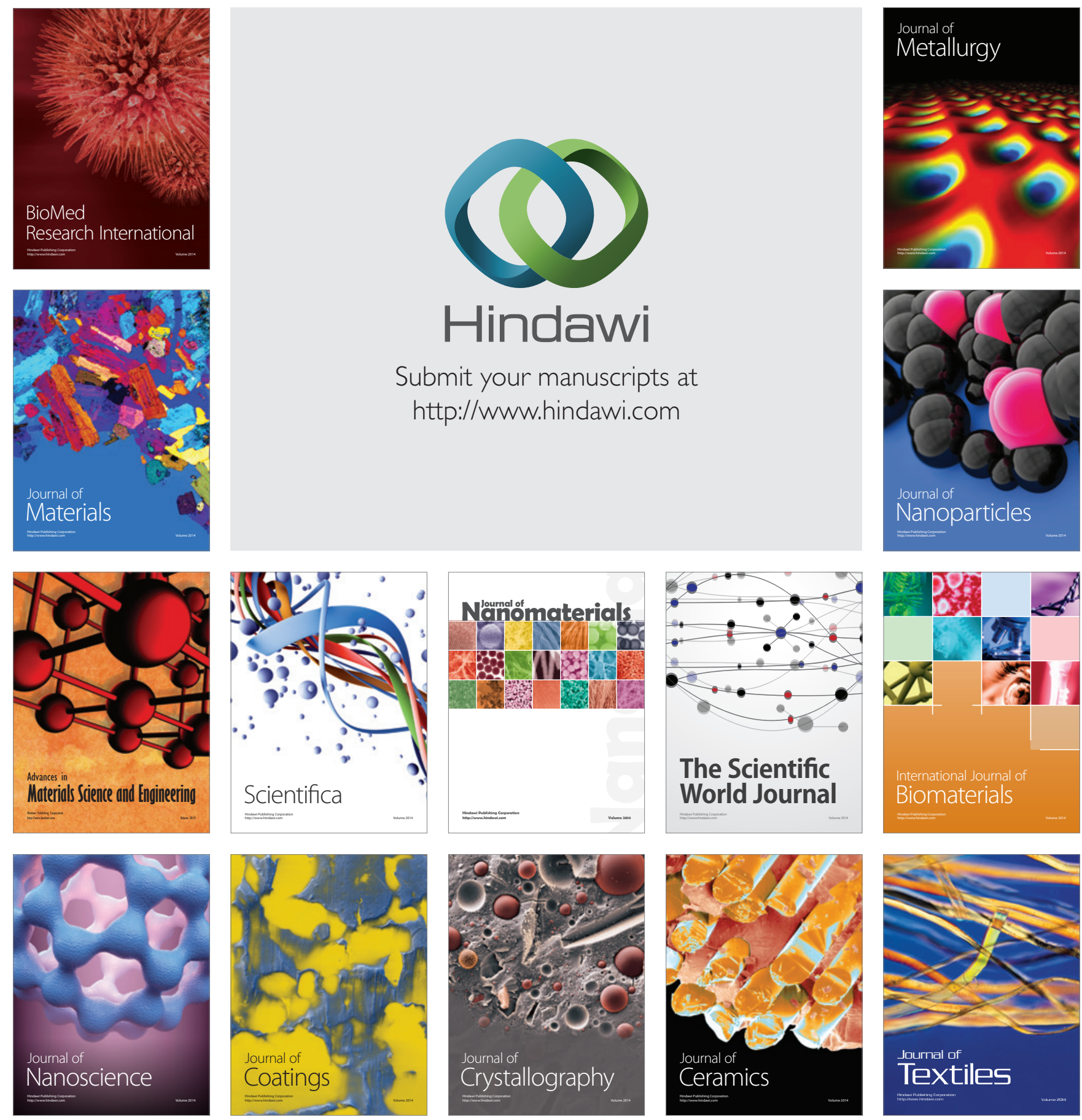